\title{
Modelling monthly precipitation with circulation weather types for a dense network of stations over Iberia
}

\author{
N. Cortesi ${ }^{1,2}$, R. M. Trigo ${ }^{2,3}$, J. C. Gonzalez-Hidalgo ${ }^{1,4}$, and A. M. $\operatorname{Ramos}^{2,5}$ \\ ${ }^{1}$ University of Zaragoza, Department of Geography, Zaragoza, Spain \\ ${ }^{2}$ University of Lisbon, CGUL, IDL, Lisbon, Portugal \\ ${ }^{3}$ Universidade Lusófona, Faculdade de Ciências e Engenharias, Lisboa, Portugal \\ ${ }^{4}$ Instituto Universitario Ciencias Ambientales (IUCA), University of Zaragoza, Zaragoza, Spain \\ ${ }^{5}$ University of Vigo, Ephyslab, Vigo, Spain
}

Correspondence to: J. C. Gonzalez-Hidalgo (jcgh@unizar.es)

Received: 30 March 2012 - Published in Hydrol. Earth Syst. Sci. Discuss.: 4 June 2012

Revised: 8 January 2013 - Accepted: 23 January 2013 - Published: 13 February 2013

\begin{abstract}
Precipitation over the Iberian Peninsula (IP) is highly variable and shows large spatial contrasts between wet mountainous regions to the north, and dry regions in the inland plains and southern areas. In this work, we modelled the relationship between atmospheric circulation weather types (WTs) and monthly precipitation for the wet half of the year (October to May) using a $10 \mathrm{~km}$ grid derived from a highdensity dataset for the IP (3030 precipitation series, overall mean density one station each $200 \mathrm{~km}^{2}$ ). We detected two spatial gradients in the relationship between WTs and precipitation. The percentage of monthly precipitation explained by WTs varies from northwest (higher variance explained) to southeast (lower variance explained). Additionally, in the IP the number of WTs that contribute significantly to monthly precipitation increase systematically from east to west. Generally speaking, the model performance is better to the west than to the east where the WTs approach produce the less accurate results. We applied the WTs modelling approach to reconstruct the long-term precipitation time series for three major stations of Iberia (Lisbon, Madrid, Valencia).
\end{abstract}

\section{Introduction}

Understanding precipitation variability is crucial for a number of reasons, namely: to assess recent significant climate trends and predictions, to calibrate regional models, to quantify changes in the hydrological cycle and to develop national and regional water planning. However, precipitation variability is difficult to assess because precipitation is one of the climate elements with highest variability at temporal and spatial scale. This explains the generalised recommendation of using high density precipitation database for regional analyses (Auer et al., 2005; Brunetti et al., 2006). In Europe one of the most interesting areas to study precipitation variability is the Iberian Peninsula (IP) because of its latitudinal location (between tropical and mid-latitudes), its western position contrasting between two water bodies (Atlantic ocean and Mediterranean Sea), and also because the disposition of the main relief chain in central and western areas is West-East, while to the East the relief is North-South. Thus, precipitation in the IP exhibits high variability at spatial and temporal domains (de Castro et al., 2005; de Luis et al., 2008).

In the IP precipitation presents the largest concentration from October to May, mainly due to the baroclinic synoptic-scale perturbations moving eastward from the Atlantic Ocean, although meso-scale convective systems can also be responsible for high rainfall rates in the eastern half of the Iberian Peninsula (Paredes et al., 2006; García-Herrera et al., 2005). In contrast, the scarce summer precipitation is mostly due to local factors and convective storms (Serrano et al., 1999). Furthermore, seasonal precipitation regimes in the IP exhibit a great variability, and dramatic changes during the second half of the 20th century have been detected, mostly as a consequence of the significant decrease of spring precipitation (de Luis et al., 2010). For these reasons, rainfall spatial variability in the IP is best detected using a 
spatially dense network of observations (Valero et al., 2009; Gonzalez-Hidalgo et al., 2009).

In recent years, significant efforts were made to reproduce precipitation behaviour in Europe with a particular focus in the IP from daily to seasonal scales (Spellman, 2000; Trigo and DaCamera, 2000; Goodess and Jones, 2002; Santos et al., 2005; Paredes et al., 2006; Lorenzo et al., 2008), using an array of methods including circulation weather types (WTs). The usefulness of WTs classification has been investigated for a wide range of applications in scientific domains, from climate to environmental areas such as air quality and natural hazards, such as forest fires, floods, droughts, avalanches and storm lightning (e.g., Vicente-Serrano and López-Moreno, 2006; Demuzere et al., 2009; Prudhomme and Genevier, 2011; Kassomenos, 2010; Ramos et al., 2011). From an hydrological perspective, WTs classifications have been used for different purposes, including their relation with precipitation (e.g., Hanggi et al., 2011; Andrade et al., 2011), extreme precipitation events (Mauran et al., 2010), forest growth (Pasho et al., 2011), drought (e.g., Fowler and Kilsby, 2002; Fleig et al., 2011) and river discharge, including floods (e.g., Wilby, 1993; Auffray et al., 2011; Fowler et al., 2000).

The main objective of all circulation classification schemes is to provide fast, objective and reproducible methods for categorising the continuum of atmospheric circulation into a reasonable and manageable number of discrete classes (types). Different methods exist for the classification of WTs, as was shown by Yarnal et al. (2001), Huth et al. (2008), and Phillip et al. (2010). These different methodological approaches can be categorised by the kind of type definition they use that can range from pure statistical (e.g., Cluster analysis and PCA) or dynamic based (e.g., intensity and direction of geostrophic wind and vorticity).

Regarding the use of WTs classification for downscaling, Bárdossy and Pegram (2011) define procedures to give confidence in the interpretation of such rainfall estimates modelled by global circulation models (GCMs). They use circulation patterns to define quantile-quantile transforms between observed and GCMs estimated rainfall in present climate and to estimate the rainfall patterns in future scenarios. Wilby (1998) modelled low-frequency rainfall events by means of airflow indices, WTs classifications and frontal frequencies. Distinct circulation weather type clusters were identified and used to construct a simplified model of daily precipitation amount. The model was calibrated against gridded data for the period 1970-1990 and used to reconstruct daily precipitation between 1875 and 1969 given the historic sequence of WTs.

In the Iberian Peninsula, Goodess and Palutikof (1998) developed a Markov Chain model to reconstruct daily precipitation at 20 locations in Guadalentín Basin (SE Spain) using 8 WTs as predictor variables. Trigo and DaCamara (2000) introduced a multiple regression model based on the three wettest WTs frequencies (the cyclonic, the south westerly and the westerly types) as predictor variables to reconstruct monthly winter rainfall totals for 18 key sites in Portugal. Spellman (2000) performed a stepwise regression analysis on a catalogue of air flow indexes to estimate monthly mean rainfall amounts for IP. Goodess and Jones (2002) expanded the regression model to include up to 14 circulation weathertypes frequencies with a forward selection method based on the F-test and applied to 20 Iberian stations. Finally, Santos et al. (2005) developed a K-mean cluster analysis over the first three principal components of the daily sea-level pressure weighted anomalies to isolate 5 weather regimes responsible for the inter annual variability of monthly winter rainfall amounts.

However, all the above-mentioned works addressing the link between monthly winter precipitation and atmospheric circulation patterns relied on very low density observation networks to validate their models, typically less than 50 stations for the whole IP. In this regard, it is perfectly reasonable to state that the spatial detail required for hydrological planning, soil erosion and many other purposes were not well captured. Also spring, summer and autumn precipitation variability have been less explored; notwithstanding October-May is the rainiest period in many areas in the IP (de Luis et al., 2010). In this sense, the recent developing of a high density spatial database of monthly precipitation in the IP combining Portugal and Spanish land (see GonzalezHidalgo et al., 2011 and Lorenzo-Lacruz et al., 2011) provides, for the first time, an opportunity to fill this gap and facilitates the relationships between weather types and precipitation totals at high spatial detail.

The research is conducted not on precipitation variability itself, but on the nature of its variability. Accordingly, the objective of this paper is twofold: firstly modelling the relationship between the monthly frequency of WTs and monthly precipitation with the highest spatial detail available at present in the IP; and secondly to show the usefulness of such an approach in long-term precipitation reconstruction. This paper is the starting step in providing the opportunity of extending the reconstruction of monthly precipitation for a very high density of stations as far back in time as 1850 , because catalogues of circulation weather types are now available since then. These reconstructions at high spatial detail would provide, in the near future, the long-term contextual framework of precipitation variability and trends in the IP, thus, allowing considering the recent changes of precipitation monthly distribution within a more global context from the middle of the 19th century. Therefore, while the main effort of this paper is focused on the evaluation of models performance during the 1948-2003 period, we will also assess the potential of this modelling approach by applying the validation with three of the longest series of monthly precipitation available in the IP.

The paper is organised as follows: section 2 describes the data, the circulation weather types used, the description of the model and the validation method. Section 3 analyses the model performance and the relative contribution to total 
monthly precipitation by each WT. In Sect. 4, we apply the model to reconstruct long-term precipitation for 3 stations (Lisbon, Madrid, Valencia). Finally, Sect. 5 contains a summary of the main results and the concluding remarks.

\section{Database, Weather Types and methods}

\subsection{Precipitation data}

We used a dense network of monthly precipitation series from MOPREDAS database (MOnthly PREcipitation DAtabase of Spain) for Spanish land (Gonzalez-Hidalgo et al., 2011) and a Portuguese database from INAG - Instituto da Água (Servicio Nacional de Informaçao de Recurcos Hídricos) (Lorenzo-Lacruz et al., 2011). In this work, the total amount of series is 3030 with 2644 relative to Spain and 386 for Portugal with the spatial distribution being shown in Fig. 1. The series come from an exhaustive quality control of original information and reconstruction processes; thus, all of the time series used in this work are complete (no gaps), and free of anomalous data and inhomogeneities (details can be found in Gonzalez-Hidalgo et al., 2011 and Lorenzo-Lacruz et al., 2011). At present, the dataset is the most complete and extensive monthly precipitation database available in IP and it allows the combining of a high station density with a long reconstruction period. In this research, the selected period for modelling WTs and precipitation relationships was 1948-2003 with an overall spatial density of 1 observatory $/ 200 \mathrm{~km}^{2}$. In general terms, the spatial distribution is quite homogeneous all over the IP, being lower in Galicia (NW), Extremadura (W) and Pyrenees (NE). In any case it should be stressed that this dataset holds the highest density of stations covering the entire IP ever used in any work. Additionally, we have used precipitation values for three very long monthly time series of IP (Lisbon, Madrid and Valencia) with common data between 1864 and 2003. Finally, monthly precipitation data was projected to UTM30 (Datum WGS1984) and interpolated over a grid of $10 \mathrm{~km} \times 10 \mathrm{~km}$ resolution with an Ordinary Kriging with a spherical variogram, for a total of 5828 land pixels.

\subsection{Circulation data and Weather Type classification}

This study relies on a very long daily historical EuropeanNorth Atlantic mean sea level pressure dataset (EMSLP) produced for the period $1850-2003$ on a $5^{\circ}$ latitude by longitude grid and complied by Ansell et al. (2006) in the framework of the EMULATE project. It was preferred to other long SLP datasets, namely the 20th Century Reanalysis dataset by Compo et al. (2011), because it relies mainly on observed data and has no influence from complex assimilation processes associated with the reconstructions from GCM. Moreover, the period covered since 1850 is longer than the time period available with the 20th Century Reanalysis (since 1871).

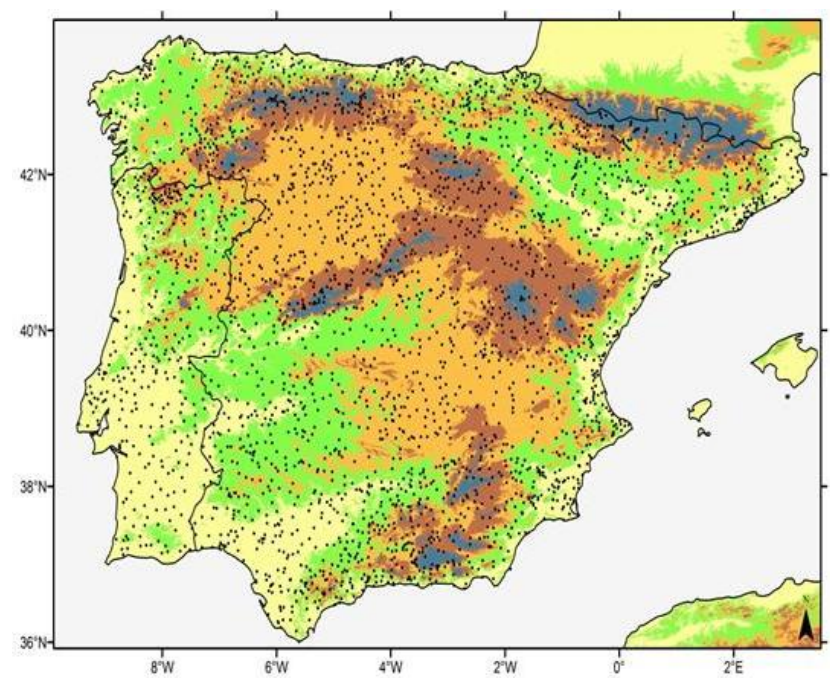

Fig. 1. Location of the 3030 monthly Iberian rainfall series used.

The daily circulation weather types affecting IP are characterised through the use of a set of indices adopted by Trigo and DaCamara (2000). This classification is based on the corresponding objective classification defined for the British Isles (Jenkinson and Collison, 1977; Jones et al., 1993) and has been broadly used for studying climate variability in the Iberian region such as trends of precipitation (Spellman, 2000; Goodess and Jones, 2002; Paredes et al., 2006), extreme events assessment such as droughts (Garcia-Herrera et al., 2007), wet winters (Vicente-Serrano et al., 2011) or even relationship with snow depth (López-Moreno and Vicente-Serrano, 2007) and modes of low frequency variability (Ramos et al., 2010). Furthermore, this methodology has also been used for the construction of climate change scenarios (Goodess and Palutikof, 1998; Miranda et al., 2002) and even linking storm lightning activity to atmospheric circulation (Tomás et al., 2004; Ramos et al., 2011).

The daily circulation weather types were determined using physical or geometrical considerations, such as the direction and strength of airflow, and degree of cyclonicity. The indices used were the following: southerly flow $\left(F_{\mathrm{S}}\right)$, westerly flow $\left(F_{\mathrm{W}}\right)$, total flow $(F)$, southerly shear vorticity $\left(Z_{\mathrm{S}}\right)$, westerly shear vorticity $\left(Z_{\mathrm{W}}\right)$ and total shear vorticity $(Z)$; they were computed using SLP values obtained for the 16 grid points (p1-p16), as shown in Fig. 2. These points were shifted $5^{\circ}$ to the east compared with the study of Trigo and DaCamara (2000), in order to centre our area in the middle of the grid. Accordingly, we used the following expressions when calculating the six atmospheric circulation indices:

$$
\begin{aligned}
F_{\mathrm{S}} & =1.305[0.25(\mathrm{p} 5+2 \mathrm{p} 9+\mathrm{p} 13)-0.25(\mathrm{p} 4+2 \mathrm{p} 8+\mathrm{p} 12)] \\
F_{\mathrm{W}} & =[0.5(\mathrm{p} 12+\mathrm{p} 13)-0.5(\mathrm{p} 4+\mathrm{p} 5)] \\
Z_{\mathrm{S}} & =0.85[0.25(\mathrm{p} 6+2 \mathrm{p} 10+\mathrm{p} 14)-0.25(\mathrm{p} 5+2 \mathrm{p} 9+\mathrm{p} 13) \\
& -0.25(\mathrm{p} 4+2 \mathrm{p} 8+\mathrm{p} 12)+0.25(\mathrm{p} 3+2 \mathrm{p} 7+\mathrm{p} 11)]
\end{aligned}
$$




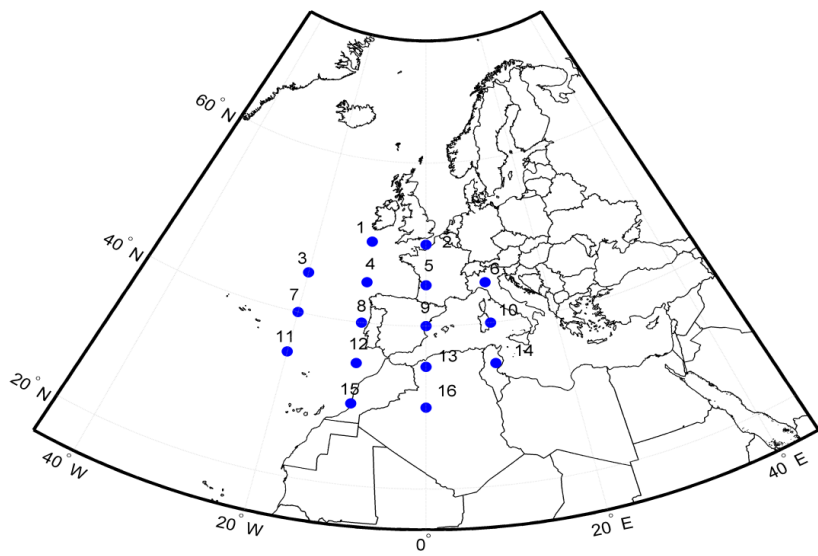

Fig. 2. Location of 16 grid points used to compute the vorticity and flow indices.

$$
\begin{aligned}
Z_{\mathrm{W}}=1.12[0.5(\mathrm{p} 15+\mathrm{p} 16)-0.5(\mathrm{p} 8+\mathrm{p} 9)] & \\
& -0.91[0.5(\mathrm{p} 8+\mathrm{p} 9)-0.5(\mathrm{p} 1+\mathrm{p} 2)] \\
F= & \left(F_{\mathrm{S}} 2+F_{\mathrm{W}} 2\right) 1 / 2 \\
Z= & Z_{\mathrm{S}}+Z_{\mathrm{W}}
\end{aligned}
$$

The conditions established to define different types of circulation are the same as those imposed in Trigo and DaCamara (2000), and the following set rules were used:

1. Direction of flow was given by $\tan ^{-1}\left(F_{\mathrm{W}} / F_{\mathrm{S}}\right), 180^{\circ}$ being added if $F_{\mathrm{W}}$ was positive. The appropriate direction was computed using an eight-point compass, allowing $45^{\circ}$ per sector.

2. If $|Z|<F$, the flow is essentially straight and was considered to be of a pure directional type (eight different cases, according to the directions of the compass).

3. If $|Z|>2 F$, the pattern was considered to be of a pure cyclonic type if $Z>0$, or of a pure anticyclonic type if $Z<0$.

4. If $F<|Z|<2 F$, the flow was considered to be of a hybrid type and was, therefore, characterised by both direction and circulation $(8 \times 2$ different types $)$.

The indices and rules mentioned allow us to define 26 different circulation Weather Types (WTs) at daily scale and for the study period, grouped in three main classes: eight pure directional types defined by their direction: N, NE, E, SE, S, SW, W and NW, two pure types controlled by the strength of geostrophic vorticity (cyclonic $\mathrm{C}$ and anticyclonic $\mathrm{A}$ ), and sixteen hybrid types (eight cyclonic and eight anticyclonic for each direction (see Fig. 3). Unlike some other authors (Jenkinson and Collison, 1977; Jones et al., 1993), an unclassified class was not defined, opting to disseminate the fairly few cases $(<2 \%)$ with possibly unclassified situations among the retained classes. This was done in order to solve the problem of the sudden increase in the unclassified class during summer for IP with Jenkinson and Collison's method detected by Martin-Vide (2002) and caused by the dominant low-pressure summer gradient over IP (Hoinka and Castro, 2003). Another weakness of Jenkinson and Collison's method is related to the absence of pressure data at other level than SLP, which can cause to obtain a high frequency of cyclonic days (both pure and hybrid) during the summer months in some IP areas, as a consequence of frequent low pressures at surface level during this season (Capel, 2000). Nevertheless, we found that this problem does not affect the IP when studied as a whole: summer frequencies for the combined 9 cyclonic WTs are always below 3 days per month.

For model performance it is often recommended to use classifications with a smaller number of WTs, because in this case each predictor WT benefits of a higher number of days per month potentially improving the reliability of their use in regression analyses. However, that was not the case in this work, thus, when we tried this approach with 8 directional WTs and pure A and pure C (10 WTs) the resulting model performance, measured with the normalised MAE score (see Sect. 2.3), was 9.3; for 8 directional WTs, 8 cyclonic WTs and pure A and pure B (i.e., $18 \mathrm{WTs}$ ) it was found to be 8.9; and finally the MAE with 26 WTs was 8.5 . This means that 26 WTs improved the regression performance up to $8 \%$ compared to what was achieved using $10 \mathrm{WTs}$ only, so the classification with 26 WTs was selected for all the following analysis.

\subsection{The model}

The analysis was applied individually to all 5828 Iberian gridded precipitation time series and for the autumn, winter and spring months (strictly speaking from October to May), because most IP precipitation falls within these months (roughly $80 \%$ ), and because absolute amounts of precipitation due to convective processes are relatively lower during the selected months. Moreover, the IP changes in summer rainfall cannot always be explained by changes in circulation, given that local factors play a major role (Mosmann et al., 2004). Interpolation of monthly precipitation was necessary because the spatial distribution of observations is not perfectly homogeneous over the IP. Finally, monthly analysis was preferred, because seasonal behaviour often masks different monthly behaviour in the IP precipitation (Serrano et al., 1999; Goodess and Jones, 2002; Gonzalez-Hidalgo et al., 2009; de Luis et al., 2010).

The model selected was a multiple linear regression (with a stepwise forward selection procedure) adapted from that of Trigo and DaCamara (2000) and of Goodess and Jones (2002). It considers the monthly frequencies (as number of days/month) of each of the 26 WTs as predictor variables, and the corresponding vector of monthly rainfall totals as the predicted variable along the study period 1948-2003 (Eq. 1). 


$$
\begin{aligned}
& \text { Year Observed } \quad \begin{array}{l}
\text { WT1 } \\
\text { 1948: }\left(\begin{array}{l}
1490 \\
1949: \\
1167 \\
\ldots \\
2003: \\
\ldots \\
1388
\end{array}\right)=\alpha_{0}+\alpha_{1} \cdot\left(\begin{array}{l}
9 \\
14 \\
\ldots \\
8
\end{array}\right)+\alpha_{2} \cdot\left(\begin{array}{l}
17 \\
12 \\
\ldots \\
20
\end{array}\right)+\ldots+\alpha_{26}\left(\begin{array}{l}
1 \\
5 \\
\ldots \\
3
\end{array}\right)(1)
\end{array}
\end{aligned}
$$

with $\alpha_{0} \geq 0$ the constant term and $\alpha_{1} \ldots \alpha_{26} \geq 0$ the coefficients for the different WTs that represent their mean daily rainfall amount $\left(\mathrm{mm} \mathrm{day}^{-1}\right)$.

The regression coefficients solve the non-negative leastsquares problem min $\left\|\mathbf{A} \alpha-\alpha_{0}\right\|$, with $\alpha=\left(\alpha_{1, \ldots,} \alpha_{26}\right)$ and A matrix of 26 column and 56 rows with the monthly WT frequencies. Coefficients were constrained as non-negative because they physically represent the mean daily rainfall amount due to the correspondent WT (that is non-negative by definition). The constant term $\alpha_{0}$ was also constrained as non-negative, to reflect the rain amount due to other processes that can not be modelled by individual WTs. Up to a maximum of ten predictors were selected for individual pixels.

We selected the stepwise forward selection procedure because the model performance largely depends on the input variables (von Storch and Zwiers, 1999), and it ensures that only relevant predictors are incorporated into the regression model. We followed this approach following Efroymson (1960) because in our case there are a large number of potential explanatory variables and no underlying theory on which to base the predictor's selection. The stepwise forward procedure also minimises the risk of over fitting of WTs in the regression, separates noise from the dominant temporal patterns of variability, and removes highly correlated predictor variables from the subset of predictors chosen for a given grid point and month. Accordingly, the selection of WTs was as follows: at each step $k$ in the process, we checked if each new potential predictor (WTs) contribution decreased the Root Mean Square Error or RMSE (see Wilks, 2006, Chapter 6.4.3.) for the selected pixel $p$, month $m$ and regression step $k$, as follows:

$\operatorname{RMSE}(p, m, k)=\sqrt{\frac{\sum_{i=1}^{n}\left(P_{i}(p, m, k)-O_{i}(p, m)\right)^{2}}{N}}$

with $P$ and $O$ being two vectors with the respectively predicted and observed monthly precipitation values for all the $N=56 \mathrm{yr}$ of the regression period (1948-2003). Remember that the RMSE is a non-negative number that tends to 0 when there is perfect agreement between reconstructions and observations. If the regression residuals $P_{i}-O_{i}$ follow a Gaussian distribution, the RMSE is also equal to the error's standard deviation of the reconstruction. The ShapiroWilk normality test applied to all grid points and months found that the residuals are normally distributed only if the RMSE of the chosen pixel and month is low (about $40 \%$ of $5828 \cdot 8$ months $=46624$ residual time series passed the test).
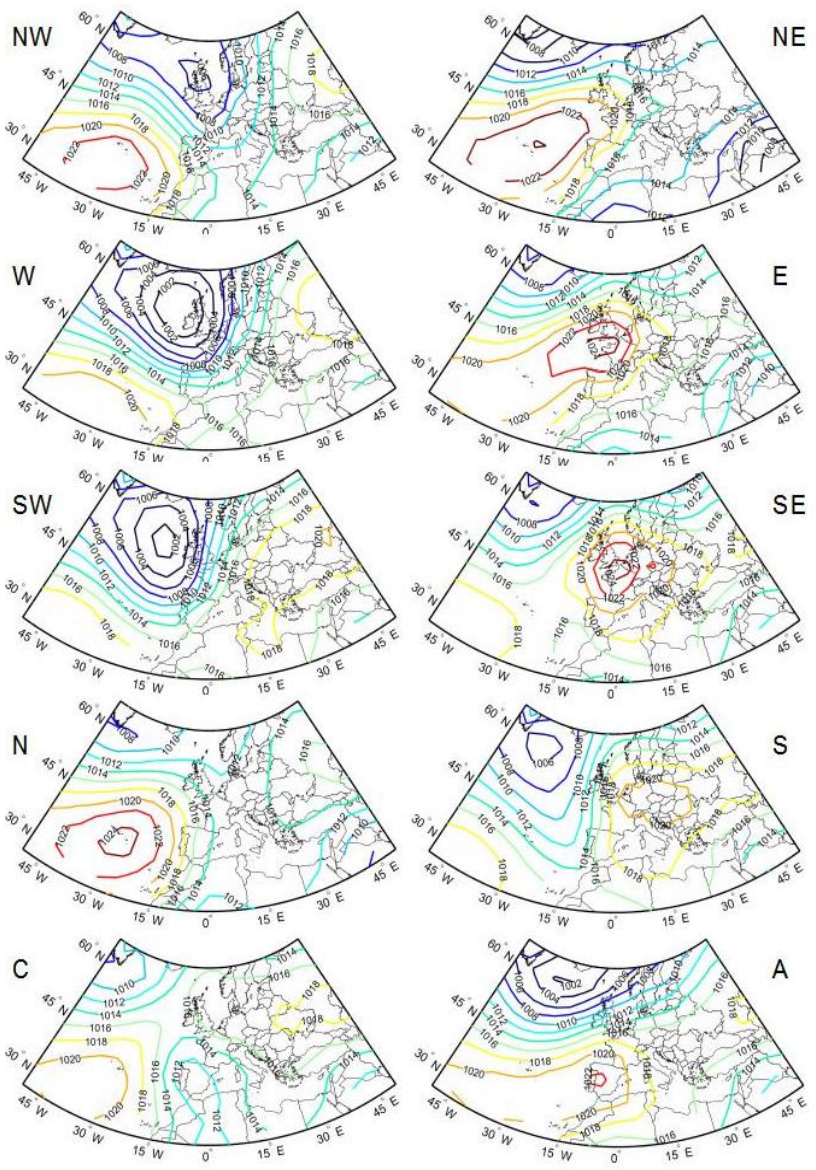

Fig. 3. Composite map of the SLP fields for the eight directional weather types (NW, N, NE, E, SE, S, SW, W), and two vorticity weather types ( $\mathrm{C}$ and $\mathrm{A})$. Hybrid types are not shown.

At the end of the selection of the best predictor WTs, a small number of them $(10 \%)$ were still moderately correlated ( $r \approx 0.4-0.6$ ). Usually, to overcome multicollinearity problems, "...whichever of the two high correlated WTs is picked at a later regression step is omitted from the final set of predictor variables" (Goodess and Jones, 2002). However, to minimise multicollinearity without removing a priori any WTs, we stopped the stepwise regression when the new variable introduced at a given step $k$ did not decrease the RMSE of at least one hundredth the mean monthly observed precipitation in comparison to the RMSE of the previous step $k-1$. This threshold is equivalent to improve the RMSE of $10 \mathrm{~mm}$ of precipitation when the mean monthly observed precipitation is $1000 \mathrm{~mm}$ (i.e., $1 \%$ ). In this way, any correlated WTs may be excluded from the regression for some grid points if they do not improve the RMSE, but may be included in the regression model relative to other pixels if they improve the RMSE, even if we know that they are highly correlated. In brief, the proposed threshold value was chosen because at the same time it minimised the numbers of predictors (reducing over fitting and multicollinearity) without significantly 
decreasing the model performance measured by the RMSE score.

Even with minimised over fitting, multicollinearity can still affect 1-2 predictor WTs, depending from month and grid time series. Heteroscedasticity is also present and increases error variances for large precipitation values. Furthermore, for WTs that are not chosen as predictors, their predicted monthly rainfall amount is exactly zero $\mathrm{mm}$, while in reality they often contribute to a few $\mathrm{mm}$ of precipitation. On the contrary, selected predictor WTs have to also account for the rainfall contribution of the excluded WTs, resulting in an overestimation of their predicted precipitation. Finally, another poor feature of the predicted time series is the relatively under-prediction of interannual variability in eastern IP, where for each month the predicted standard deviations are significantly lower (up to ten time smaller) than observed for the majority of time series (not shown, but with a spatial pattern similar to Fig. 4).

Model validation was performed by means of a leave-oneout cross validation over the regression period for all 5828 grid time series of monthly precipitation of IP. Specifically, for each pixel and month the experiment was carried out was as follows: one year of monthly precipitation data was excluded, and then we estimated the model parameters for the remaining years and the predicted precipitation for the year discarded was then calculated.

The use of the RMSE also as indicator of goodness of model should be avoided, because it varies with variability in the squared errors, so it is impossible to discern the degree to which the RMSE reflects average errors and to what extent it reflects variability in the distribution of squared errors (Willmott and Matsuura, 2005 and 2006). Instead, we evaluated the model performance with three error indexes: the Mean Absolute Error (MAE), the Mean Bias Error (MBE) and the $D$ of Willmott (also called "Index of Agreement"). MAE index is less sensitive to large reconstruction errors than the RMSE and describes the average error alone. It can range from 0 to infinity and, of course, lower values are better. MBE provides relevant information about the average over- or under-prediction, so it can assume also negative values. Willmott's $D$ scales with magnitude of the variables, is bounded between 0 and 1 (perfect prediction), retains mean information and does not amplify outliers (Willmott, 1981, 1982; Willmott et al., 2012). Computational forms of the three indexes are given below:

$$
\begin{aligned}
& \operatorname{MAE}(p m)=\bar{O}(p, m)^{-1} N^{-1} \sum_{i=1}^{N}\left|P_{i}(p, m)-O_{i}(p, m)\right| \\
& \operatorname{MBE}(p m)=\bar{O}(p, m)^{-1} N^{-1} \sum_{i=1}^{N}\left(P_{i}(p, m)-O_{i}(p, m)\right)
\end{aligned}
$$

$$
D(p, m)=\frac{\sum_{i=1}^{N}\left|P_{i}(p, m)-O_{i}(p, m)\right|}{\sum_{i=1}^{N}\left(\left|P_{i}(p, m)-\bar{O}(p, m)\right|+\left|O_{i}(p, m)-\bar{O}(p, m)\right|\right)}
$$

Where $\bar{O}$ is the mean monthly observed precipitation during the study period. Both MBE and MAE were normalised for $\bar{O}$ to compare values obtained for different pixels and months, while the form of $D$ in Eq. (5) is the modified Index of Agreement suggested by Willmott et al. (1985), which is much less sensitive to outliers than the original formulation.

\section{Results}

\subsection{Model validation}

The results of the cross-validation analysis are shown in the following set of Figs. 4 and 5 that focus on different aspects of the evaluation procedure. The area with the lowest MAEvalues $(<5 \%$ of $\bar{O})$ is located to the northwest (north of Portugal and Spanish border, Fig. 4). Also low MAE-values between $5 \%$ and $10 \%$ can be observed to the north, west and southwest except in April and May, when high values are restricted to the northern areas of Portugal, and surrounding areas of Spain. The highest values are found in the Mediterranean fringe although the area with MAE $>15 \%$ varies between months. It is interesting to notice that the Ebro basin to the northeast inland of IP usually exhibits moderate MAEvalues ranging between $10 \%-15 \%$. In general the spatial range of MAE-values increases in April and May suggesting that spring precipitation depends more on local factors than on synoptic patterns of atmospheric circulation.

The obtained spatial pattern of MAE parameter suggests that the capacity of using regional atmospheric circulation to explain the Iberian precipitation regime decreases significantly along an axis predominately from northwest to southeast.

For each month, the distribution of the MBE is quite heterogeneous and does not show any clear spatial pattern in the IP (figure not shown); normalised MBE is greater than $\pm 2 \%$ only for $4.6 \%$ of pixel-month pairs and greater than $\pm 5 \%$ only for $0.4 \%$ of cases.

The spatial distribution of Willmott's $D$ presents relatively similar results to those attained by MAE. In particular the $D$ scores obtained for the 5828 time series also reveal a main gradient oriented NW-SE (Fig. 5). The highest D-values, corresponding to better model performance, are located along the Atlantic and northern Cantabric coast to the northwest (a maximum of 0.86 in December at Quinta Formosa, north of Portugal), while the lowest D-values are found on the Mediterranean coast (a minimum of 0.09 in October at Tuejar, west of Valencia, Spain). During April and May, the areas with the lowest D-values spread along the southern 


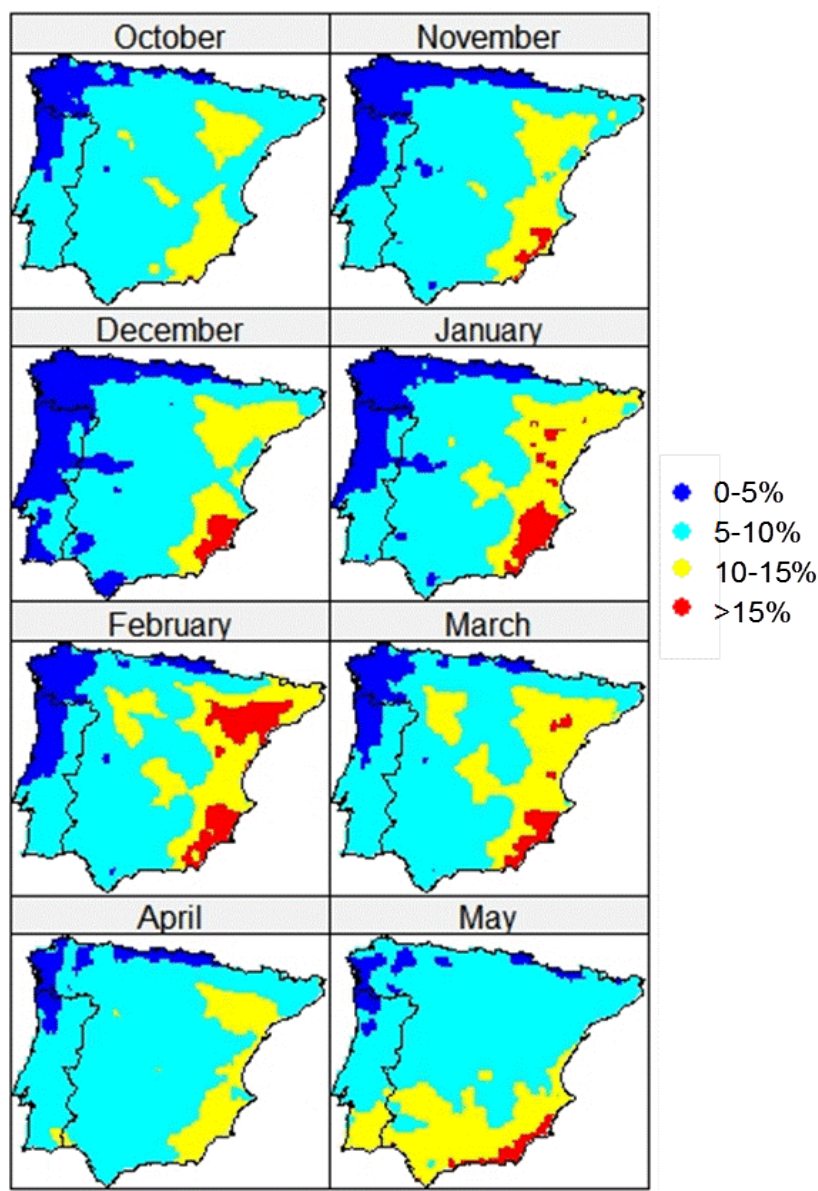

Fig. 4. Spatial and temporal distribution of MAE of predicted rainfall amount for each month from October to May normalised for the mean monthly observed precipitation. Low percentages represent a better agreement between reconstruction and observations.

coastland areas (Andalucía) and the Ebro Valley up to the Cantabric Coast.

A monthly comparison of the goodness of the predictions for the whole IP can be found in Table 1. Each of the three monthly error indexes was averaged over all the 5828 IP pixels. Although spatial information is lost, this table allows identifying which month is better reconstructed: December (normalised $\mathrm{MAE}=7.7 \%, \mathrm{MBE}=0.0 \%$ and $D=0.65$ ), while February and May are the months with the poorest performance, having the highest MAE and lower $D$ index, respectively.

\subsection{Number and type of predictor WTs}

The spatial distribution of the number of predictors retained (i.e., WT) for the models are shown for each month in Fig. 6. A small number of time series (5\%) were modelled with one predictor only; all of them are concentrated over the Mediterranean Coast. Time series with 2 predictors are spread over a wider area (17\%), particularly in March. However, the most

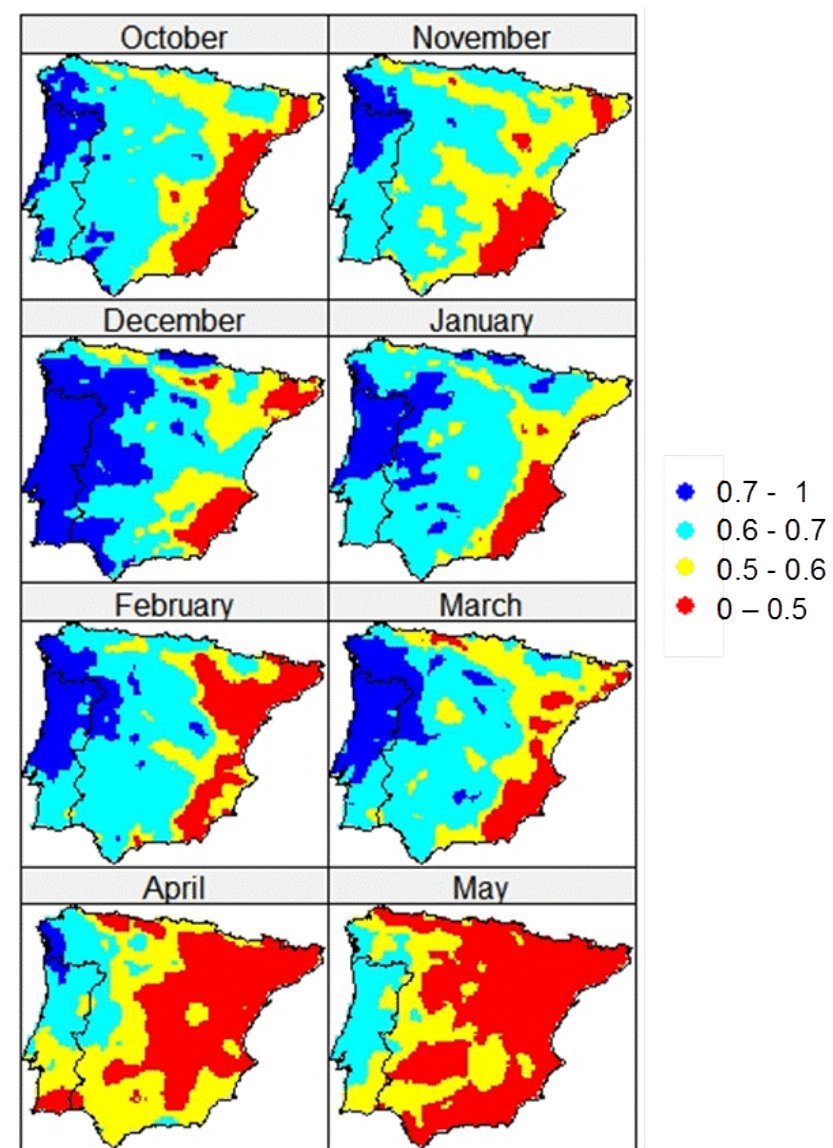

Fig. 5. Spatial and temporal distribution Willmott $D$ applied to predicted and observed precipitation for each month from October to May. High values near 1 represent a better agreement between reconstruction and observations.

Table 1. Global monthly normalised MAE, MBE and D indexes from October to May. Each index was averaged over all the 5828 pixels.

\begin{tabular}{lrrrrrrrr}
\hline Index & Oct & Nov & Dec & Jan & Feb & Mar & Apr & May \\
\hline MAE & $8.2 \%$ & $8.0 \%$ & $7.7 \%$ & $8.5 \%$ & $9.3 \%$ & $9.0 \%$ & $8.6 \%$ & $9.1 \%$ \\
MBE & $0.1 \%$ & $-0.2 \%$ & $0.0 \%$ & $0.1 \%$ & $-0.2 \%$ & $0.4 \%$ & $0.0 \%$ & $0.2 \%$ \\
$D$ & 0.60 & 0.60 & 0.65 & 0.63 & 0.61 & 0.62 & 0.52 & 0.48
\end{tabular}

frequent time series are those characterised with 3 predictors ( $28 \%$ ), being homogeneously distributed all over IP. On the other side models requiring either 4 predictors ( $24 \%$ of pixels) or 5 predictors $(15 \%)$ tend to be clustered in the western and central sectors of IP. Models with 6 predictors $(6 \%)$ are usually not found on the Mediterranean Coast, but are numerous in Portugal and Andalusia in southern Spain. Finally, models requiring up to 7 and 8 predictors (the $1 \%$ and $0.2 \%$, respectively) are mostly confined to southern Portugal.

In general terms, there is a rough longitudinal spatial gradient in the number of WTs from West (more) to the East (less) (Fig. 7). Temporally, the mean number of WTs scores 


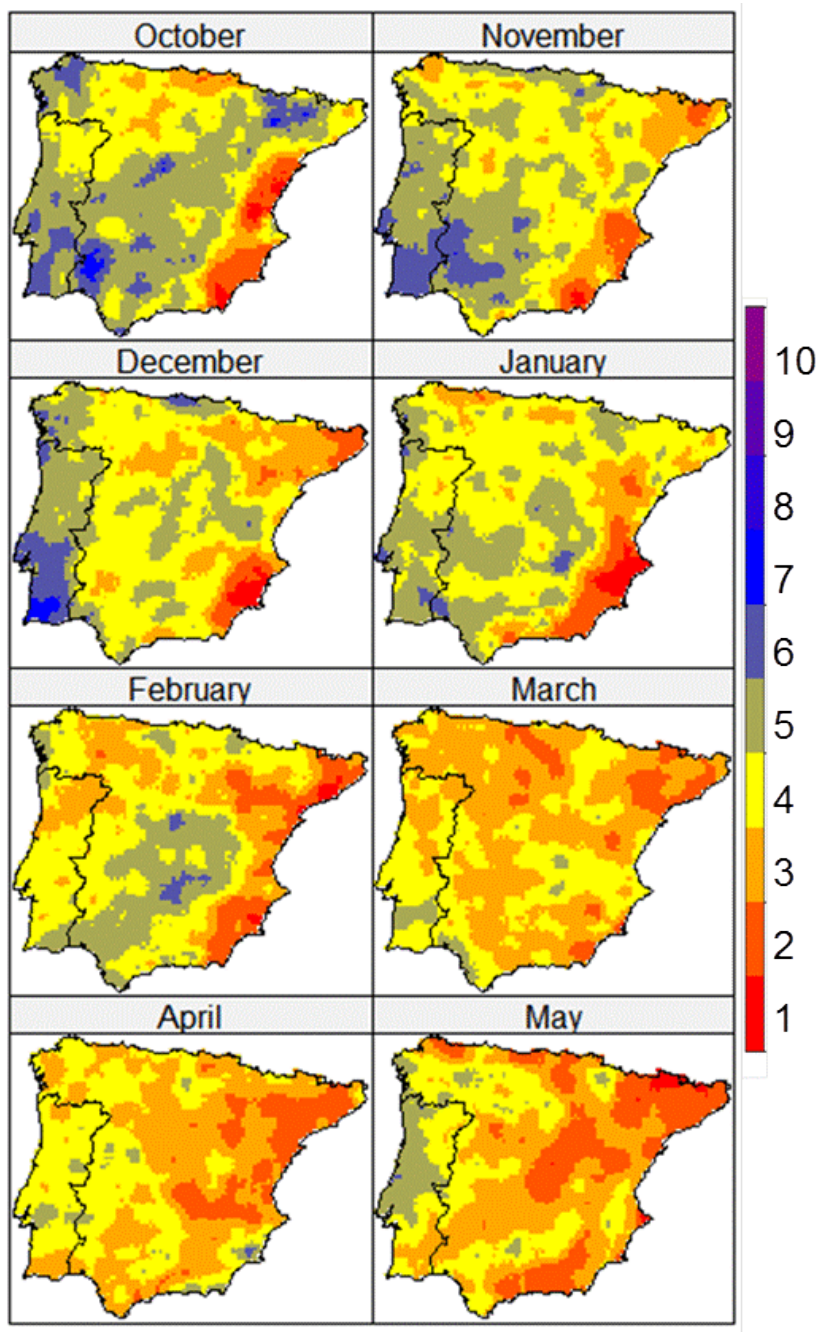

Fig. 6. Spatial and temporal distribution of the number of predictor WTs of the regression model for each month from October to May.

its maximum in October (3.9 WTs mean value), November (3.8 WTs), December (3.6 WTs) and January (3.5 WTs), while the minimum value correspond to May ( $2 \mathrm{WTs}$ ), March (2.8 WTs) and April (2.9 WTs). Usually time series with a high number of WTs have lower MAE scores than series with few predictors.

For a given time series and month, the mean predicted rainfall amount of the $i$-esim WT can be obtained by multiplying its regression coefficient $\alpha_{i}$ in Eq. (1) for its mean monthly frequency (as number of days in a month) during the study period 1948-2003. This value can be normalised for the mean observed precipitation to get the mean percentage of WT predicted rainfall for the given pixel and month. Averaging these values for all the 5828 time series during the same month we obtain the mean monthly percentage of modelled precipitation by WT over all Iberian Peninsula, presented in Table 2. Please note that columns do not sum to 100 because we did not include the constant term and, additionally, because values are calculated dividing the amount $(\mathrm{mm})$
Table 2. Average estimated WT percentage contribution to total monthly Iberian precipitation during 1948-2003.

\begin{tabular}{lrrrrrrrrr}
\hline WT & Oct & Nov & Dec & Jan & Feb & Mar & Apr & May & Mean \\
\hline NE & 1.1 & 0.9 & 0.2 & 0.0 & 0.4 & 1.2 & 0.8 & 0.2 & 0.6 \\
E & 0.1 & 0.1 & 0.0 & 0.8 & 4.0 & 0.6 & 0.2 & 0.0 & 0.7 \\
SE & 0.1 & 0.7 & 0.2 & 0.4 & 0.2 & 0.1 & 0.1 & 0.0 & 0.2 \\
S & 3.7 & 0.6 & 0.3 & 0.5 & 0.7 & 0.1 & 0.0 & 2.4 & 1.0 \\
SW & 8.1 & 7.3 & 15.9 & 18.9 & 14.6 & 8.8 & 6.0 & 3.3 & 10.4 \\
W & 19.0 & 19.0 & 23.8 & 27.9 & 28.7 & 31.1 & 13.2 & 13.4 & 22.0 \\
NW & 1.0 & 10.4 & 6.1 & 8.5 & 1.4 & 0.4 & 3.3 & 4.5 & 4.4 \\
N & 3.2 & 1.2 & 0.9 & 2.6 & 1.6 & 6.9 & 0.9 & 8.1 & 3.2 \\
\hline Sum & 36.3 & 40.2 & 47.4 & 59.6 & 51.6 & 49.2 & 24.5 & 31.9 & 42.5 \\
\hline C & 11.5 & 12.7 & 9.9 & 18.1 & 2.6 & 13.4 & 23.2 & 20.9 & 14.0 \\
C.NE & 1.6 & 0.1 & 1.5 & 0.0 & 0.0 & 1.4 & 3.5 & 2.3 & 1.3 \\
C.E & 4.2 & 1.8 & 2.5 & 0.2 & 1.2 & 0.5 & 0.4 & 0.2 & 1.4 \\
C.SE & 0.7 & 2.4 & 4.2 & 0.2 & 1.2 & 0.5 & 0.4 & 0.2 & 1.2 \\
C.S & 0.7 & 3.4 & 0.2 & 0.1 & 0.1 & 1.0 & 0.0 & 0.3 & 0.7 \\
C.SW & 2.7 & 6.3 & 3.2 & 1.1 & 4.1 & 1.6 & 0.4 & 0.1 & 2.4 \\
C.W & 6.5 & 2.2 & 0.6 & 1.0 & 0.5 & 0.3 & 0.0 & 0.7 & 1.5 \\
C.NW & 1.2 & 0.0 & 1.1 & 0.1 & 1.2 & 0.0 & 0.8 & 0.8 & 0.7 \\
C.N & 0.3 & 0.5 & 0.4 & 0.0 & 3.0 & 0.0 & 0.0 & 0.2 & 0.6 \\
\hline Sum & 29.4 & 29.4 & 23.6 & 20.7 & 13.4 & 18.4 & 29.3 & 25.9 & 23.8 \\
\hline A & 0.1 & 0.0 & 0.0 & 0.0 & 0.0 & 0.1 & 0.0 & 0.0 & 0.0 \\
A.NE & 0.8 & 0.0 & 0.0 & 0.1 & 0.0 & 0.0 & 0.6 & 1.5 & 0.4 \\
A.E & 0.0 & 0.2 & 0.0 & 0.0 & 0.4 & 0.0 & 0.0 & 0.5 & 0.1 \\
A.SE & 0.0 & 0.2 & 0.0 & 0.0 & 0.0 & 0.0 & 0.4 & 0.1 & 0.1 \\
A.S & 0.0 & 0.0 & 0.0 & 0.0 & 0.2 & 0.5 & 0.5 & 0.0 & 0.2 \\
A.SW & 0.0 & 0.0 & 0.1 & 0.6 & 0.2 & 0.1 & 0.0 & 0.0 & 0.1 \\
A.W & 0.4 & 0.8 & 0.4 & 0.1 & 0.2 & 2.4 & 1.8 & 0.0 & 0.8 \\
A.NW & 1.4 & 1.4 & 1.3 & 0.8 & 0.1 & 0.1 & 0.4 & 0.1 & 0.7 \\
A.N & 0.1 & 0.7 & 0.4 & 0.1 & 0.2 & 0.0 & 0.7 & 0.0 & 0.3 \\
\hline Sum & 2.7 & 3.1 & 2.3 & 1.7 & 1.3 & 3.1 & 4.4 & 2.2 & 2.7 \\
\hline Total & 68.4 & 72.7 & 73.3 & 82.0 & 66.3 & 70.7 & 58.2 & 60.0 & 69.1 \\
\hline & & & & & & & & &
\end{tabular}

of precipitation predicted by the amount $(\mathrm{mm})$ of precipitation observed. The percentage of relative contribution of each WT to the observed monthly precipitation varies considerably from pixel to pixel and from month to month. The global monthly relative contribution of all WTs can be found in the last row of Table 2. The highest global values are found in January $(82.0 \%)$, the lowest in April (58.2\%). On average, the global relative contribute of all 26 WTs to mean monthly rainfall from October to May is about $69.1 \%$, and the four wettest WTs contribute around $50 \%$ to total monthly precipitation, namely the westerly $(22.0 \%)$, Pure Cyclonic $(14.0 \%)$, southwesterly (10.4\%) and northwesterly (4.4\%) (see column Mean of Table 2).

The contribution of westerly (W) weather types rise gradually from October to March and then decrease until AprilMay when the lowest values are reached; the same pattern is observed with the southwesterly (SW), while the maximum is achieved in January. On the contrary, the contribution of NW and N types shows high monthly oscillations from October to May (maximum in November and May, respectively). Pure cyclonic (C) type is a special case because it drops abruptly to $2.6 \%$ in February, while during all other months it never falls below $9 \%$ and maximum value are achieved in April-May. 
It is worth noting that on a monthly average, the 8 directional WTs contribute to $42.5 \%$ of total monthly precipitation, the 9 cyclonic WTs contribute to $23.8 \%$, while the 9 anticyclonic WTs only contribute $2.7 \%$. On the other hand, the maximum mean value relative contribution to total precipitation of directional WTs can be observed in winter months, while for cyclonic WTs this maximum contribution is located in spring or autumn months.

With the aim of summarising results, we present in Fig. 7, the spatial distribution of relative WTs contribution to monthly precipitation. The mean value of the precipitation contribution by the WTs identified by model, irrespectively of their number, suggests some interesting features at spatial level. In central, western and southwestern areas the mean value contribution of WTs to monthly precipitation is usually over $70 \%$, and sometimes even above $90 \%$. However, in a few restricted areas less than $50 \%$ of monthly precipitation is reproduced by the WTs based models, particularly along the Mediterranean coast, and inland areas such as the Ebro Basin, particularly in February, April and May. A second interesting result can be appreciated in the northern mountainous sector of Iberia; this area is very humid, but the WTs only reproduce a maximum of $70 \%$ of monthly precipitation that could be due to a systematic effect of mountain chain parallel to the coast enhancing a local forcing.

The spatial variation of the different WTs contribution to monthly precipitation is high. We present an example for January (Fig. 8) because this is the month in which the model prediction achieves higher proportion of total precipitation by WTs $(82.0 \%)$.

During January the selected WTs vary greatly from region to region. The $\mathrm{W}, \mathrm{SW}$ and $\mathrm{C}$ types are the most spatially distributed and they contribute to a monthly precipitation over $10 \%$ of monthly totals. The relevance of their contribution extends over all areas with the exception of the northern coast, were the NW and N predictors are predominate with their anticyclonic counterparts (A.NW and A.N, not shown in Fig. 8), and Mediterranean fringe. The S type is globally weaker, but strongly affects Mediterranean coastland (Fig. 8). Pure Cyclonic (C) is the wettest of the cyclonic types (Fig. 8) and has a strong influence (>30\%) on precipitation in the northeast (Ebro Valley and Catalonia) and southern coastland of Andalucía); it also contributes to a lesser extent (between 10-30\%) over extended areas of inland IP, but it does not contribute to the northwest (Galicia), northern coastland and to the southeast (Fig. 8). The other cyclonic WTs contribute with a very low proportion of monthly precipitation, do not show any clear spatial pattern, or have a small influence on a limited area.

The majority of the anticyclonic types were rarely selected as predictor WTs; only anticyclonic A.NW and A.N types reveal a moderate contribution along the northern coast, while anticyclonic A.SW contributes scarcely to rainfall in Galicia and Andalusia (south of Spain).

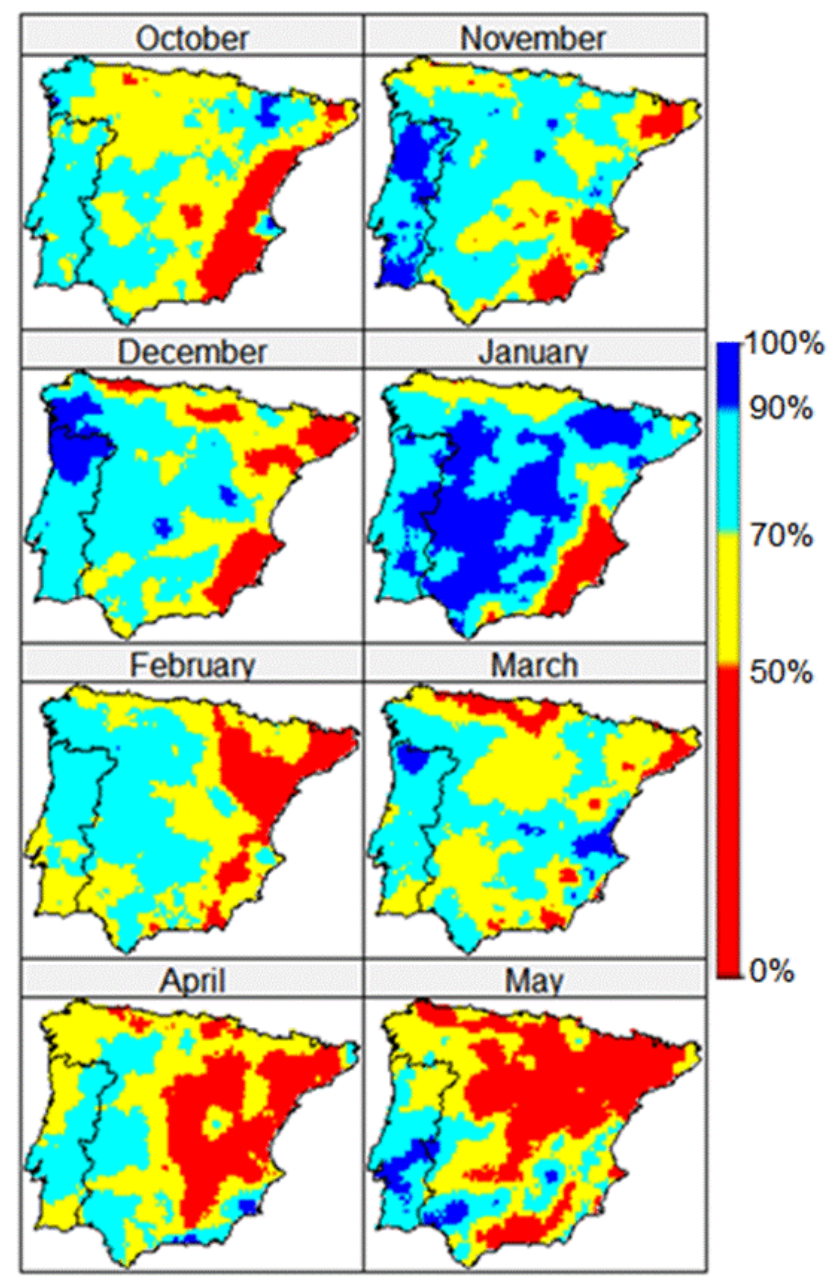

Fig. 7. Spatial and temporal distribution of the relative contribution of WTs to monthly precipitation.

\section{An example of reconstruction of long term monthly precipitation in the IP}

The regression model has been applied to three very long monthly precipitation series of IP, specifically Lisbon, Madrid and Valencia, corresponding to a strong W-E latitudinal gradient conditions from oceanic (Lisbon), to continental (Madrid) to Mediterranean coast (Valencia). According to previous results obtained with the validation procedure (see Figs. 4 and 5) we ought to expect a good agreement between observed and reconstructed time series for Lisbon and Madrid and to a lesser extent in Valencia. It should be stressed that the seasonal cycle is not equal for these three stations with the precipitation regime in Lisbon showing a clear maximum during the winter months. In Madrid the precipitation regime is dominated by a symmetric bimodal spring-autumn, while in Valencia, the bimodal rainfall regime exhibits a maximum during autumn. 
Table 3. Normalised monthly MAE values for Lisbon, Madrid and Valencia stations measured for two different validation periods: 19482003 (same as calibration period) and 1864-1947. The percentage difference between the two validation periods appears in the third line of each station.

\begin{tabular}{lrrrrrrrr}
\hline Lisbon & Oct & Nov & Dec & Jan & Feb & Mar & Apr & May \\
\hline $1948-2003$ & $7.5 \%$ & $5.7 \%$ & $4.9 \%$ & $5.1 \%$ & $6.3 \%$ & $6.8 \%$ & $8.0 \%$ & $9.3 \%$ \\
$1864-1947$ & $7.5 \%$ & $6.5 \%$ & $5.5 \%$ & $5.8 \%$ & $6.6 \%$ & $7.4 \%$ & $8.8 \%$ & $10.5 \%$ \\
$\Delta$ in $\%$ & $0.1 \%$ & $13.4 \%$ & $12.3 \%$ & $14.8 \%$ & $4.4 \%$ & $7.9 \%$ & $9.2 \%$ & $12.7 \%$ \\
\hline Madrid & Oct & Nov & Dec & Jan & Feb & Mar & Apr & May \\
\hline $1948-2003$ & $9.1 \%$ & $8.8 \%$ & $8.5 \%$ & $9.7 \%$ & $10.1 \%$ & $10.4 \%$ & $9.4 \%$ & $9.7 \%$ \\
$1864-1947$ & $10.4 \%$ & $8.9 \%$ & $9.3 \%$ & $11.5 \%$ & $11.1 \%$ & $13.3 \%$ & $11.0 \%$ & $9.5 \%$ \\
$\Delta$ in $\%$ & $15.3 \%$ & $1.6 \%$ & $8.5 \%$ & $18.4 \%$ & $10.1 \%$ & $28.8 \%$ & $17.2 \%$ & $-2.1 \%$ \\
\hline Valencia & Oct & Nov & Dec & Jan & Feb & Mar & Apr & May \\
\hline $1948-2003$ & $9.4 \%$ & $11.7 \%$ & $11.1 \%$ & $15.3 \%$ & $14.9 \%$ & $14.5 \%$ & $12.7 \%$ & $13.1 \%$ \\
$1864-1947$ & $8.3 \%$ & $15.2 \%$ & $11.4 \%$ & $14.7 \%$ & $16.4 \%$ & $17.1 \%$ & $13.2 \%$ & $14.4 \%$ \\
$\Delta$ in $\%$ & $-11.7 \%$ & $29.2 \%$ & $2.7 \%$ & $-3.8 \%$ & $10.1 \%$ & $18.2 \%$ & $3.8 \%$ & $10.6 \%$ \\
\hline
\end{tabular}

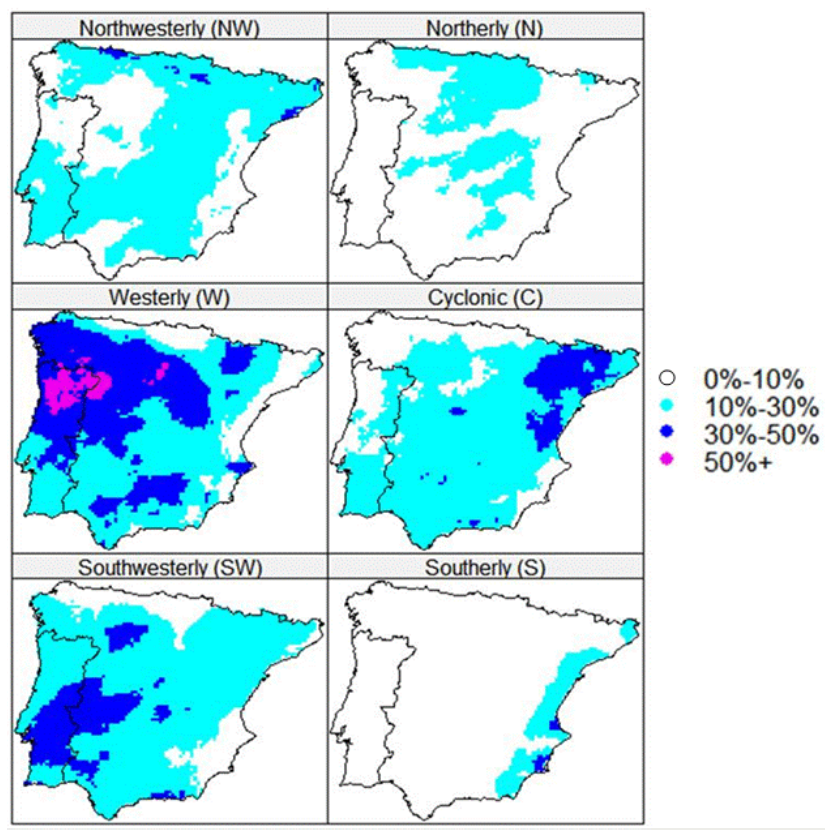

Fig. 8. Spatial distribution of the relative contributes to total January precipitation for NW, N, W, C, SW and S WTs.

In Table 3, we show the normalised MAE scores calculated for the independent validation period 1864-1947 and compared these with normalised MAE scores obtained for the reference period (1948-2003) used for calibration and validation purposes. The difference between the reference MAE and the MAE achieved during 1864-1947 was divided by the reference MAE, in order to compute the relative change (as a percentage of the MAE over the reference period.
Considering only the reference period 1948-2003, it is evident that the normalised MAE score really improves from east to west, ranging from $15.3 \%$ for Valencia in January, down to a minimum of $5.1 \%$ for Lisbon in the same month. As expected the normalised MAE scores obtained for the independent validation period (1864-1947) are higher (i.e., worse) than scores for the reference period (1948-2003).

In order to compare observed and modelled values we show (Fig. 9) the predicted and observed January values during the whole period (1864-2003) at Lisbon, Madrid and Valencia stations. Lisbon station shows a good agreement even during the first period 1864-1947. Madrid station shows a good agreement during the reference period 1948-2003, however, during 1864-1947 the MAE scores are higher. Valencia station always shows the highest MAE values, even during the reference period, so the model is not able to reconstruct the rainfall in this area as is capable for inland and western IP, as already discussed. Finally, two of the three stations (Lisbon and Madrid) show a general overestimation of predicted January precipitation during the second part of the 19th century. Such overestimation could be totally or partially due to known bias in the EMSLP dataset during the second half of the 19th century, which increases the frequencies of some WTs for some months, particularly the southwesterly WT, one of the main rainfall contributors in IP.

The overall quality of the model can also be appreciated visually through the analysis of scatter-plots (Fig. 10) that present observed vs. predicted precipitation for January and also relative to the three observatories described above. The figure shows how the model achieves the best fit over the westernmost station (Lisbon) declining as we move towards the central (Madrid) and the eastern (Valencia) stations. 

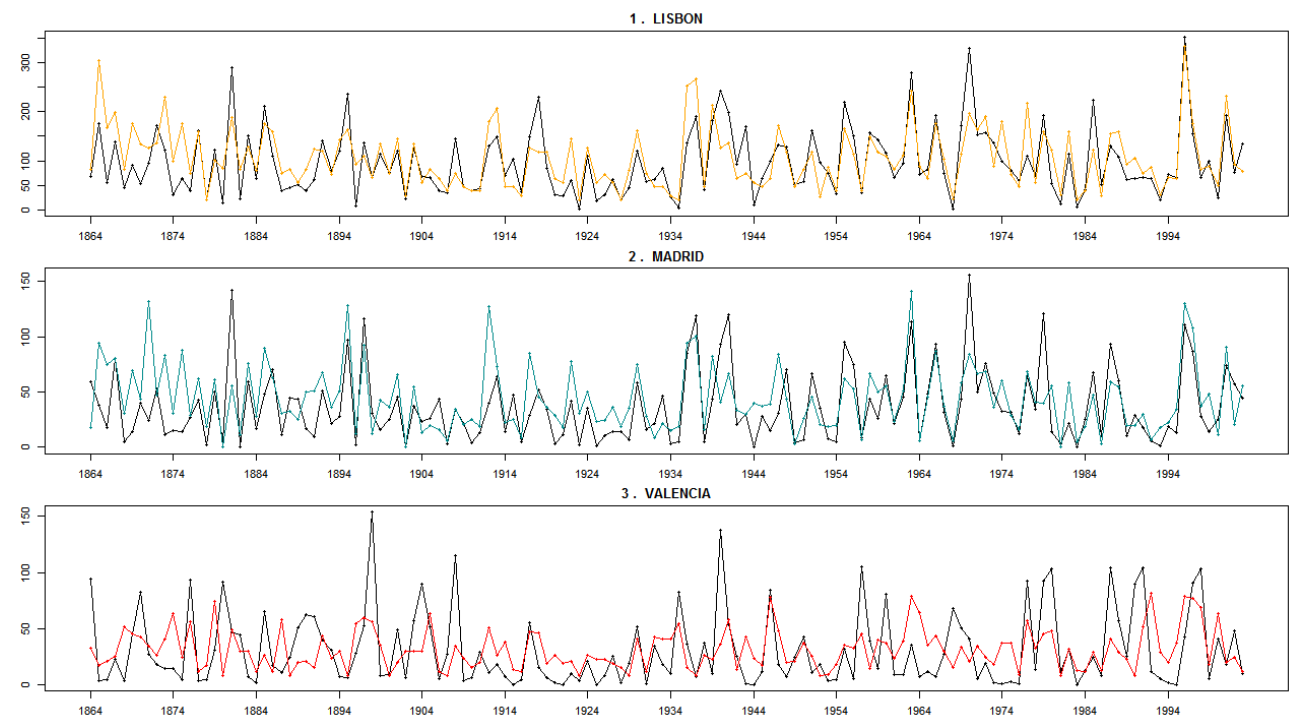

Fig. 9. January observed monthly precipitation (black line) and predicted precipitation (colour line) for the three long-term stations of Valencia, Madrid and Lisbon.
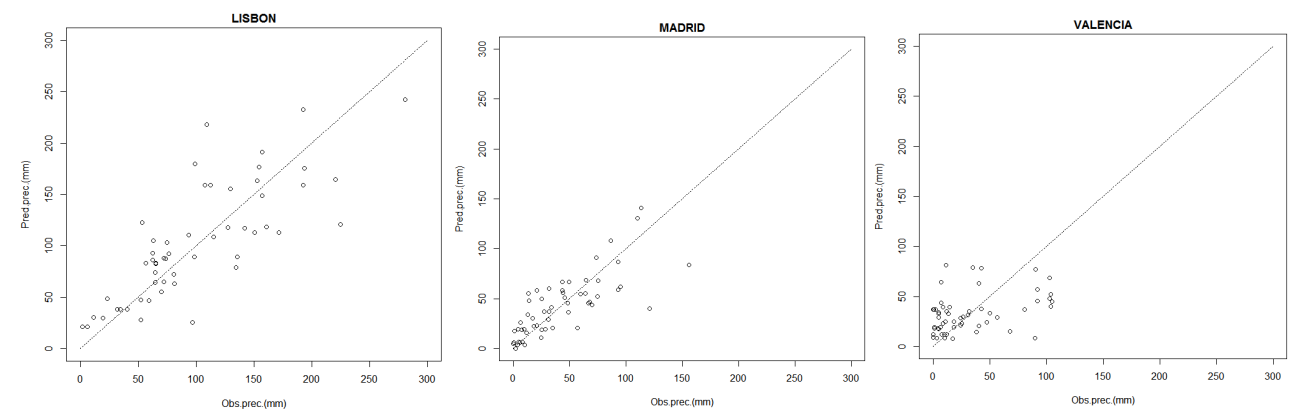

Fig. 10. Scatterplot of January total precipitation between observed and modelled values (1948-2003) for Lisbon, Madrid and Valencia.

\section{Discussion and conclusions}

The circulation weather type classification devised by Trigo and DaCamara (2000) has been successfully applied as potential predictors of monthly precipitation in the IP after validation procedure over the 5828 Iberian grid points for the $56 \mathrm{yr}$ of the reference period (1948-2003). The results of the regression model show qualitative agreement with previous studies (Goodess and Jones, 2002; Spellman, 2000; Trigo and DaCamara, 2000), and improved the spatial detail information. Thus, the first novelty of the present work is related with the very high resolution achieved that improves all previous efforts developed for the IP.

Using monthly data instead of daily presents both advantages and disadvantages. Beyond the first and more intuitive advantage of the higher density available with the monthly precipitation networks, monthly data also reduces the existing uncertainties of the precipitation records, given the difficulty of having reliable and homogeneous daily precipitation datasets. In our case, each monthly series is complete during all the study period, so station density is constant in time, and homogeneously distributed all over the IP, while for daily series this is often a problematic issue. In particular, for the $56 \mathrm{yr}$ studied here (1948-2003), the number of available stations with complete daily data over the entire IP is scarce and without a good coverage in many areas. However, we also know that using monthly data has an important disadvantage of masking the spatial and temporal uncertainty associated to extreme events and very specific atmospheric configurations (e.g., Vicente-Serrano et al., 2009). Moreover, with a daily dataset it is not necessary to introduce a regression model to calculate the values of WT mean daily rainfall amount represented by the $\alpha_{1 \ldots} \alpha_{26}$ coefficients in Eq. (1), from which all the predicted precipitation values are derived: they can be directly obtained from the observed daily data, without introducing all the uncertainties typical of a regression model (due to multicollinearity, heteroscedasticity, non-Gaussian residuals, etc., see Sect. 2.3 for a detailed description).

As expected, the most accurate predictions are achieved in western locations of IP and there is a progressive decrease 
in accuracy to the east, where spatial variability of rainfall is considerably higher and cannot be captured as well by these models (Martín-Vide, 2001). This deficiency is partially due to the fact that precipitation events are not entirely related with synoptic scale atmospheric circulation, being also related with small scale convective phenomena, orographic effects, etc. This means that even in non-summer seasons, modelling outcomes along the Mediterranean fringe are obtained with less confidence in a well-defined area between mountain chain and coast line. Unfortunately this is an area where credible impact scenarios are of most value due to the growing mismatch between water resource supply and demand, and where human and economic activities are concentrated in the Iberian Peninsula.

In general terms, the models achieve the best results where precipitation is more regular and more abundant (western areas), and has less accuracy on the contrary (Mediterranean coast). In this context, the precipitation variability that characterises the eastern Mediterranean coastal sector of IP is associated to a very low number (1 or 2 ) of WTs. In this regard, past (and future) changes of monthly frequency of just 1 or 2 WTs classes are bound to have a significant impact on precipitation totals. On the other hand, the precipitation variability observed in western sectors of IP is well reproduced by the model and appear to be related with a higher number of WTs, thus, ensuring that the precipitation in this area is less susceptible to changes in frequency of just 1 or 2 classes. As a consequence, temporal changes in WTs responsible of precipitation affecting the Mediterranean coast would have more dramatic effects than single changes in WTs affecting to the west.

The general results of the study reflect with high accuracy a very well defined division of IP accordingly the WT analysed, that were detected primarily at seasonal scale in Muñoz and Rodrigo (2006), i.e., the northern coastland, the Mediterranean fringe, including the Ebro basin and the central west areas, with different response to WT approach. In particular over the Eastland areas the effects of SST of Mediterranean Sea, and also the increment of convective processes, with very local effects, could be one of the main reasons of the lower accuracy of the WT approach presented here. The spatial distribution of main mountain chain seems to be a primarily factor of these distribution.

In addition, the regression model offers different possibilities of application. In this paper, it has been applied to three very long monthly precipitation series of Iberia Peninsula, specifically Lisbon, Madrid and Valencia for the 18641947, showing a strong West-East latitudinal gradient from oceanic (Lisbon), to continental (Madrid) to Mediterranean coast (Valencia) conditions with Lisbon having the better performance and Valencia the worst. It was shown, therefore, that the use of WTs can be of added value when reconstructing precipitation time series particularly in specific areas of IP. Comparing EMSLP with other long daily SLP database, such as the NCAR-NCEP or the 20th Century
Project, would help improving reconstruction accuracy by removing the EMSLP overestimation of some WT frequencies during the 2 nd half of the 19th century. Other possible improvement of the method could be achieved expanding daily SLP field to include also information given by geopotential heights (although reducing the period for reconstruction given the lack of available data for the XIX century), or including as potential predictors pressure variables that are obtained in the Jenkinson and Collison classification (average pressure, zonal flow, meridian flow, vorticity, etc.) and not only the WT frequency series. We foresee the use of these models in follow-up work in order to obtain monthly precipitation at very high density since the beginning of 20th century, and locally from the 1850 s with reasonable accuracy.

Acknowledgements. Contact Grant Sponsor Ministerio de Ciencia e Innovación Spanish Goverment), project Impactos Hidrológicos del Calentamiento Global en España (HIDROCAES) (CGL201127574-C02-01). Nicola Cortesi is a FPI-PhD student supported by Ministerio de Cultura, (Spanish Goverment). Alexandre M. Ramos was supported through Portuguese Science Foundation (FCT) through grant BD/46000/2008. Ricardo Trigo was supported by Project DISASTER - GIS database on hydro-geomorphologic disasters in Portugal: a tool for environmental management and emergency planning (PTDC/CS-GEO/103231/2008), funded by the Portuguese Foundation for Science and Technology (FCT).

Edited by: M. Werner

\section{References}

Andrade, C., Santos, J. A., Pinto, J. G., and Corte-Real, J.: Largescale atmospheric dynamics of the wet winter 2009-2010 and its impact on hydrology in Portugal, Clim. Res., 46, 29-41, 2011.

Ansell, T., Jones, P. D., Allan, R. J., Lister, D., Parker, D. E., Brunet-India, M., Moberg, A., Jacobeit, J., Brohan, P., Rayner, N., Aguilar, E., Alexandersson, H., Barriendos, M., Brazdil, R., Brandsma, T., Cox, N., Drebs, A., Founda, D., Gerstengarbe, F., Hickey, K., Jonsson, T., Luterbacher, J., Nordli, O., Oesterle, H., Rodwell, M., Saladie, O., Sigro, J., Slonosky, V., Srnec, L., Suarez, A., Tuomenvirta, H., Wang, X., Wanner, H., Werner, P., Wheeler, D., and Xoplaki, E.: Daily mean sea level pressure reconstructions for the European - North Atlantic region for the period 1850-2003, J. Climate, 19, 2717-2742, 2006.

Auer, I., Bohm, R., Jurkovic, A., Orlik, A., Potzmann, R., Schoner, W., Ungersbock, M., Brunetti, M., Nanni, T., Maugeri, M., Briffa, K., Jones, P., Epthymiadis, D., Mestre, O., Moisselin, J. M., Begert, M., Brazdill, R., Bochniker, O., Cegnar, T., GajicCapka, M., Zaninovic, K., Majstorovic, Z., Szalai, S., Szentimrey, T., and Mercalli, L.: A new instrumental precipitation dataset for greater Alpine region for the period 1800-2002, Int. J. Climatol., 25, 139-166, 2005.

Auffray, A., Clavel, A., Jourdain, S., Ben Daoud, A., Sauquet, E., Lang, M., Obled, C., Panthou, G., Gautheron, A., Gottardi, F., and Garcon, R.: Reconstructing the hydrometeorological scenario of the 1859 flood of the Isere river, Houille Blanche-Revue Internationale de l'eau, 1, 44-50, 2011. 
Bárdossy, A. and Pegram, G.: Downscaling precipitation using regional climate models and circulation patterns toward hydrology, Water Resour. Res., 47, W04505, doi:10.1029/2010WR009689, 2011

Brunetti, M., Maugeri, M., Monti, F., and Nanni, T.: Temperature and precipitation variability in Italy in the last two centuries from homogenised instrumental time series, Int. J. Climatol., 26, 345381,2006

Capel, J. J.: El clima de la Peninsula Iberica, Ariel, Barcelona, 2000. Compo, G. P., Whitaker, J. S., Sardeshmukh, P. D., Matsui, N., Allan, R. J., Yin, X., Gleason, Jr. B. E., Vose, R. S., Rutledge, G., Bessemoulin, P., Bronnimann, S., Brunet, M., Crouthamel, R. I., Grant, A. N., Groisman, P. Y., Jones, P. D., Kruk, M. C., Kruger, A. C., Marshall, G. J., Maugeri, M., Mok, H. Y., Nordli, Ø., Ross, T. F., Trigo, R. M., Wang, X. L., Woodruff, S. D., and Worley, S. J.: The Twentieth Century Reanalysis Project, Q. J. R. Meteorol. Soc., 137, 1-28, 2011.

de Castro, M., Martin-Vide, J., and Alonso, S.: El clima de España: pasado, presente y escenarios de clima para el siglo XXI, in Impactos del cambio climático en España, Ministerio Medio Ambiente, Madrid, 2005.

de Luis, M., Gonzalez-Hidalgo, J. C., Longares, L. A., and Stepanek, P.: Regílmenes estacionales de la precipitacion en la vertiente mediterranea de la Península Ibérica, in Cambio climatico regional y sus impactos, Asociacion Española de Climatología, Tarragona, 81-90, 2008.

de Luis, M., Brunetti, M., Gonzalez-Hidalgo, J. C., Longares, L. A., and Martin-Vide, J.: Changes in seasonal precipitation in the Iberian Peninsula during 1946-2005, Global Planet. Change, 74, 27-33, 2010.

Demuzere, M., Trigo, R. M., Vila-Guerau de Arellano, J., and van Lipzig, N. P. M.: The impact of weather and atmospheric circulation on $\mathrm{O}_{3}$ and $\mathrm{PM}_{10}$ levels at a rural mid-latitude site, Atmos. Chem. Phys., 9, 2695-2714, doi:10.5194/acp-9-2695-2009, 2009.

Efroymson, M. A.: Multiple regression analysis. Mathematical Methods for Digital Computers, edited by: Ralston, A. and Wilf, H. S., Wiley, 1960.

Fleig, A. K., Tallaksen, L. M., Hisdal, H., and Hannah, D. M.: Regional hydrological drought in north-western Europe: linking a new Regional Drought Area Index with weather types, Hydrol. Process., 25, 1163-1179, 2011.

Fowler, H. J. and Kilsby, C. G.: A weather-type approach to analysing water resource drought 10 in the Yorkshire region from 1881 to 1998, J. Hydrol., 262, 177-192, 2002.

Fowler, H. J., Kilsby, C. G., and O'Connell, P. E.: A stochastic rainfall model for the assessment of regional water resource systems under changed climatic condition, Hydrol. Earth Syst. Sci., 4, 263-281, doi:10.5194/hess-4-263-2000, 2000.

García-Herrera, R., Hernández, H., Paredes, D., Barriopedro, D., Correoso, J. F., and Prieto, L.: A MASCOTTE-based characterization of MCSs over Spain, 2000-2002, Atmos. Res., 73, 261282,2005

García-Herrera, R., Paredes, D., Trigo, R. M., Trigo, I. F., Hernández, H., Barriopedro, D., and Mendes, M. T.: The outstanding 2004-2005 drought in the Iberian Peninsula: the associated atmospheric circulation, J. Hydrometeorol., 8, 483-498, 2007.
Gonzalez-Hidalgo, J. C., Lopez-Bustins, J. A., Stepanek, P., MartinVide, J., and de Luis, M.: Monthly precipitation trends on the Mediterranean fringe of the Iberian Peninsula during the $25 \mathrm{sec}-$ ond half of the 20th century (1951-2000), Int. J. Climatol., 29, 1415-1429, 2009.

Gonzalez-Hidalgo, J. C., Brunetti, M., and de Luis, M.: A new tool for monthly precipitation analysis in Spain: MOPREDAS database (Monthly precipitation trends December 1945-November 2005), Int. J. Climatol., 31, 715-731, 2011.

Goodess, C. M. and Jones, P. D.: Links between circulation and changes in the characteristics 30 of Iberian rainfall, Int. J. Climatol., 22, 1593-1615, 2002.

Goodess, C. M. and Palutikof, J. P.: Development of daily rainfall scenarios for southeast Spain using a circulation-type approach to downscaling, Int. J. Climatol., 18, 1051-1083, 1998.

Hanggi, P., Jetel, M., Kuttel, M., Wanner, H., and Weingartner, R.: Weather type-related trend analysis of precipitation in Switzerland, Hydrol. Wasserbewirts., 55, 140-154, 2011.

Hoinka, K. P. and Castro, M.: The Iberian Peninsula thermal low, Q. J. Roy. Meteorol. Soc., 129, 1491-1511. doi:10.1256/qj.01.189, 2003.

Huth, R., Beck, C., Philipp, A., Demuzere, M., Ustrnul, Z., Cahynova, M., Kysely, J., and Tveito, O. E.: Classifications of Atmospheric Circulation Patterns, Annals of the New York of Sci-ences, 1146, 105-152, 2008.

Jenkinson, A. F. and Collison, F. P.: An initial climatology of gales over the North Sea, Synoptic Climatology Branch Memorandum, No. 62, Meteorological Office, Bracknell, 1977.

Jones, P. D., Hulme, M., and Briffa, K. R.: A comparison of Lamb circulation types with an objective classification scheme, Int. J. Climatol., 13, 655-663, 1993.

Kassomenos, P.: Synoptic circulation control on wild fire occurrence, Phys. Chem. Earth, 35, 544-552, 2010.

Lorenzo, M. N., Taboada, J. J., and Gimeno, L.: Links between circulation weather types and teleconnection patterns and their influence on precipitation patterns in Galicia (NW Spain), Int. J. Climatol., 28, 1493-1505, 2008.

Lorenzo-Lacruz, J., Vicente-Serrano, S. M., López-Moreno, J. I., González-Hidalgo, J. C., and Morán-Tejeda, E.: The response of Iberian rivers to the North Atlantic Oscillation, Hydrol. Earth Syst. Sci., 15, 2581-2597, doi:10.5194/hess-15-25812011, 2011.

Lopez-Moreno, J. I. and Vicente-Serrano, S. M.: Atmospheric circulation influence on the interannual variability of snowpack in the Spanish Pyrenees during the second half of the twentieth century, Nord. Hydrol., 38, 33-44, 2007.

Kassomenos, P.: Synoptic circulation control on wild fire occurrence, Phys. Chem. Earth, 35, 544-552, 2010.

Maraun, D., Rust, H. W., and Osborn, T. J.: Synoptic airflow and UK daily precipitation extremes: development and validation of a vector generalised linear model, Extremes, 13, 133-153, 2010.

Martin-Vide, J.: Limitations of an objective weather-typing system for the Iberian Peninsula, Weather, 56, 248-250, 2001.

Martin-Vide, J.: Aplicación de la clasificación sinóptica de Jenkinson y Collison a días de precipitación torrencial en el este de España, in: La información climática como herramienta de gestión ambiental, edited by: Cuadrat, J. M., Vicente, S. M., and Saz, M. A., 123-127, 2002. 
Miranda, P., Coelho, F., Tomé , A., and Valente, A.: 20th century Portuguese climate and climate scenarios, Climate Change in Portugal: Scenarios, Impacts and Adaptation Measures, SIAM, edited by: Santos, F. D., Forbes, K., and Moita, R., Gradiva, 2783, 2002.

Mosmann, V., Castro, A., Fraile, R., and Dessens, J., and Sánchez, J. L.: Detection of statistically significant trends in the summer precipitation of mainland Spain, Atmos. Res., 70, 43-53, 2004.

Muñoz, D. and Rodrigo, F. S.: Seasonal rainfall variations in Spain (1912-2000) and their links to atmospheric circulation, Atmos. Res., 81, 94-110, 2006.

Paredes, D., Trigo, R. M., García-Herrera, R., and Trigo, I. F.: Understanding precipitation changes in Iberia in early spring: weather typing and storm-tracking approaches, J. Hydrometeorol., 7, 101-113, 2006.

Pasho, E., Camarero, J. J., de Luis, M., and Vicente-Serrano, S. M.: Spatial variability in large-scale and regional atmospheric drivers of Pinus halepensis growth in eastern Spain, Agr. Forest Meteorol., 151, 1106-1119, 2011.

Philipp, A., Bartholy, J., Beck, C., Erpicum, M., Esteban, P., Fettweis, X., Huth, R., James, P., Jourdain, S., Kreienkamp, F., Krenner, T., Lykoudis, S., Michalides, S. C., Pianko-Kluczynska, K., Post, P., Rasilla-Alvarez, D., Schiemann, R., Spekat, A., and Tymvios, F. S.: Cost733cat - a database of weather and circulation type classifications, Phys. Chem. Earth, 35, 360-373, 2010.

Prudhomme, C. and Genevier, M.: Can atmospheric circulation be linked to flooding in Europe?, Hydrol. Process., 25, 1180-1190, 2011.

Ramos, A. M., Lorenzo, M. N., and Gimeno, L.: Compatibility between modes of low frequency variability and Circulation Types: a case study of the North West Iberian Peninsula, J. Geophys. Res., 115, D02113, doi:10.1029/2009JD012194, 2010.

Ramos, A. M., Ramos, R., Sousa, P., Trigo, R. M., Janeira, M., and Prior, V.: Cloud to ground lightning activity over Portugal and its association with Circulation Weather Types, Atmos. Res., 101, 84-101, 2011.

Santos, J. A., Corte-Real, J., and Leite, S. M.: Weather regimes and their connections to the winter rainfall in Portugal, Int. J. Climatol., 25, 33-50, 2005.

Serrano, A., Garcia, J. A., Mateos, V. L., Cancillo, M. L., and Garrido, J.: Monthly modes of 20 variation of precipitation over the Iberian peninsula, J. Climate, 12, 2894-2919, 1999.

Spellman, G.: The use of an index-based regression model for precipitation analysis on the Iberian Peninsula, Theor. Appl. Climatol., 66, 229-239, 2000.

Tomás, C., Pablo, F., and Soriano, F. L.: Circulation weather types and cloud to ground flash density over Iberian Peninsula, Int. J. Climatol., 24, 109-123, 2004.

Trigo, R. M. and DaCamara, C. C.: Circulation weather types and their impact on the precipitation regime in Portugal, Int. J. Climatol., 20, 1559-1581, 2000.
Valero, F., Martín, M. L., Sotillo, M. G., Morata, A., and Luna, M. Y.: Characterization of the autumn Iberian precipitation from long term datasets: comparison between observed and hindcasted data, Int. J. Climatol., 29, 527-541, 2009.

Vicente-Serrano, S. and Lopez-Moreno, J. I.: The influence of atmospheric circulation at different spatial scales on winter drought variability through a semi-arid climatic gradient in Northeast Spain, Int. J. Climatol., 26, 1427-1453, 2006.

Vicente-Serrano, S. M., Santiago Beguería, López-Moreno, J. I., El Kenawy, A. M., and Angulo, M.: Daily atmospheric circulation events and extreme precipitation risk in Northeast Spain: the role of the North Atlantic Oscillation, Western Mediterranean Oscillation, and Mediterranean Oscillation, J. Geophys. Res.-Atmos., 114, D08106, doi:10.1029/2008JD011492, 2009.

Vicente-Serrano, S. M., Trigo, R. M., Liberato, M. L. R., LóopezMorenom, J. I., Lorenzo-Lacruz, J., Beguería, S., Morán-Tejeda, H., and El Kenawy, A.: Extreme winter precipitation in the Iberian Peninsula, 2010: anomalies, driving mechanisms and future projections, Clim. Res., 46, 51-65, 2011.

von Storch, H. and Zwiers, F. W.: Statistical analysis in climate research, Cambridge University Press, UK, 1999.

Wilby, R. L.: The influence of variable weather patterns on river water quantity and quality regimes, Int. J. Climatol., 13, 447459, 1993.

Wilby, R. L.: Modelling low-frequency rainfall events using airflow indices, weather patterns and frontal frequencies, J. Hydrol., 213, 380-392, 1998.

Wilks, D. S.: Statistical Methods in the Atmospheric Sciences: An Introduction, International Geophysics, Series 59, Academic Press, St. Louis, Missouri, USA, 2006.

Willmott, C. J.: On the validation of models, Phys. Geogr., 2, 184 194, 1981.

Willmott, C. J.: Some comments on the evaluation of model performance, B. Am. Meteorol. Soc., 63, 1309-1313, 1982.

Willmott, C. J. and Matsuura, K.: Advantages of the mean absolute error (MAE) over the root mean square error (RMSE) in assessing average model performance, Clim. Res., 30, 79-82, 2005.

Willmott, C. J. and Matsuura, K.: On the use of dimensioned measures of error to evaluate the performance of spatial interpolators, Int. J. Geogr. Inf. Sci., 20, 89-102, 2006.

Willmott, C. J., Ackleson, S. G., Davis, R. E., Feddema, J. J., Klink, K. M., Legates, D. R., O’Donnell, J., and Rowe, C. M.: Statistics for the evaluation of model performance, J. Geophys. Res., 90, 8995-9005, 1985.

Willmott, C. J., Robeson, S. M., and Matsuura, K.: A refined index of model performance, Int. J. Climatol., 32, 2088-2094, doi:10.1002/joc.2419, 2012.

Yarnal, B., Comrie, A. C., and Frakes, B., and Brown, D. P.: Developments and prospects in synoptic climatology, Int. J. Climatol., 21, 1923-1950, 2001. 